\title{
Intracellular protein degradation: from a vague idea thru the lysosome and the ubiquitin-proteasome system and onto human diseases and drug targeting*
}

\author{
A Ciechanover ${ }^{*, 1}$ \\ ${ }^{1}$ Cancer and Vascular Biology Research Center, The Rappaport Faculty of \\ Medicine and Research Institute, Technion-Israel Institute of Technology, \\ Haifa 31096, Israel \\ * Corresponding author: A Ciechanover, Faculty of Medicine, Technion-Israel \\ Institute of Technology, Efron Street, Bat Galim, PO Box 9649, Haifa 31096, \\ Israel. Tel: + 972-4-829-5379, 5356; Fax: + 972-4-852-3947, 3922; \\ E-mail: c_tzachy@netvision.net.il
}

Received 09.5.05; accepted 10.5.05

Edited by G Melino

\begin{abstract}
Between the 1950s and 1980s, scientists were focusing mostly on how the genetic code is transcribed to RNA and translated to proteins, but how proteins are degraded has remained a neglected research area. With the discovery of the lysosome by Christian de Duve, it was assumed that cellular proteins are degraded within this organelle. Yet, several independent lines of experimental evidence strongly suggested that intracellular proteolysis is largely nonlysosomal, but the mechanisms involved remained obscure. The discovery of the ubiquitin-proteasome system resolved the enigma. We now recognize that degradation of intracellular proteins is involved in regulation of a broad array of cellular processes, such as cell cycle and division, regulation of transcription factors, and assurance of the cellular quality control. Not surprisingly, aberrations in the system have been implicated in the pathogenesis of human disease, such as malignancies and neurodegenerative disorders, which led subsequently to an increasing effort to develop mechanismbased drugs.

Cell Death and Differentiation (2005) 12, 1178-1190.

doi:10.1038/sj.cdd.4401692
\end{abstract}

Keywords: ubiquitin; proteasome; protein degradation; lysosome

*Nobel Lecture 2004, C The Nobel Foundation 2004

\footnotetext{
Abbreviations: ODC, ornitihine decarboxylase; G6PD, glucose6-phosphate dehydrogenase; PEPCK, phosphoenol-pyruvate carboxykinase; TAT, tyrosine aminotransferase; APF-1, ATP-dependent Proteolysis Factor 1 (ubiquitin); UBIP, ubiquitous immunopoietic polypeptide (ubiquitin); MCP, multicatalytic proteinase complex (26S proteasome); CP, $20 \mathrm{~S}$ core particle (of the proteasome); RP, 19S regulatory particle (of the proteasome)
}

\section{Introduction}

The concept of protein turnover is hardly 60 years old. Beforehand, body proteins were viewed as essentially stable constituents that were subject to only minor 'wear and tear': dietary proteins were believed to function primarily as energyproviding fuel, which were independent of the structural and functional proteins of the body. The problem was hard to approach experimentally, as research tools were not available. An important research tool that was lacking at that time were stable isotopes. While radioactive isotopes were developed earlier by George de Hevesy (de Hevsey G, Chemistry 1943. In Nobel Lectures in Chemistry 1942-1962. World Scientific 1999, pp. 5-41), they were mostly unstable and could not be used to follow metabolic pathways). The concept that body structural proteins are static and the dietary proteins are used only as a fuel was challenged by Rudolf Scheonheimer in Columbia University in New York city. Schoenheimer escaped from Germany and joined the Department of Biochemistry in Columbia University founded by Hans T Clarke. ${ }^{1-3}$ There he met Harold Urey, who was working in the Department of Chemistry and who discovered deuterium, the heavy isotope of hydrogen, a discovery that enabled him to prepare heavy water, $\mathrm{D}_{2} \mathrm{O}$. David Rittenberg who had recently received his Ph.D. in Urey's laboratory, joined Schoenheimer, and together they entertained the idea of 'employing a stable isotope as a label in organic compounds, destined for experiments in intermediary metabolism, which should be biochemically indistinguishable from their natural analog. ${ }^{1}$ Urey later succeeded in enriching nitrogen with ${ }^{15} \mathrm{~N}$, which provided Schoenheimer and Rittenberg with a 'tag' for amino acids and as a result for the study of protein dynamics. They discovered that following administration of ${ }^{15} \mathrm{~N}$-lablled tyrosine to rat, only $\sim 50 \%$ was recovered in the urine, 'while most of the remainder is deposited in tissue proteins. An equivalent of protein nitrogen is excreted. ${ }^{4}$ They further discovered that from the half that was incorporated into body proteins, 'only a fraction was attached to the original carbon chain, namely to tyrosine, while the bulk was distributed over other nitrogenous groups of the proteins', ${ }^{4}$ mostly as an $\alpha \mathrm{NH}_{2}$ group in other amino acids. These experiments demonstrated unequivocally that the body structural proteins are in a dynamic state of synthesis and degradation, and that even individual amino acids are in a state of dynamic interconversion. Similar results were obtained using ${ }^{15} \mathrm{~N}$-lablled leucine. ${ }^{5}$ This series of findings shattered the paradigm in the field at that time that: (1) ingested proteins are completely metabolized and the products are excreted, and (2) body structural proteins are stable and static. Schoenheimer was invited to deliver the prestigious Edward K Dunham lecture at Harvard University, where he presented his revolutionary findings. After his untimely tragic death in 1941, his lecture 
notes were edited by Hans Clarke, David Rittenberg and Sarah Ratner, and were published in a small book by Harvard University Press. The editors called the book 'The Dynamic State of Body Constituents', ${ }^{6}$ adopting the title of Schoenheimer's presentation. In the book, the new hypothesis is clearly presented: 'The simile of the combustion engine pictured the steady-state flow of fuel into a fixed system, and the conversion of this fuel into waste products. The new results imply that not only the fuel, but the structural materials are in a steady state of flux. The classical picture must thus be replaced by one which takes account of the dynamic state of body structure'. However, the idea that proteins are turning over was not accepted easily and was challenged as late as the mid-1950s. For example, Hogness et al. ${ }^{7}$ studied the kinetics of $\beta$-galactosidase in Escherichia coli and summarized their findings: 'To sum up: there seems to be no conclusive evidence that the protein molecules within the cells of mammalian tissues are in a dynamic state. Moreover, our experiments have shown that the proteins of growing $E$. coli are static. Therefore, it seems necessary to conclude that the synthesis and maintenance of proteins within growing cells is not necessarily or inherently associated with a 'dynamic state'. While the experimental study involved the bacterial $\beta$-galactosidase, the conclusions were broader, including also the authors' hypothesis on mammalian proteins. The use of the term 'dynamic state' was not incidental, as they challenged directly Schoenheimer's studies.

Now, after more then six decades of research in the field and with the discovery of the lysosome and later the complex ubiquitin-proteasome system with its numerous tributaries, it is clear that the area has been revolutionized. We now realize that intracellular proteins are turning over extensively, that this process is specific, and that the stability of many proteins is regulated individually and can vary under different conditions. From a scavenger, unregulated and nonspecific end process, it has become clear that proteolysis of cellular proteins is a highly complex, temporally controlled and tightly regulated process that plays major roles in a broad array of basic pathways. Among these processes are cell cycle, development, differentiation, regulation of transcription, antigen presentation, signal transduction, receptor-mediated endocytosis, quality control and modulation of diverse metabolic pathways. Subsequently, it has changed the paradigm that regulation of cellular processes occurs mostly at the transcriptional and translational levels, and has set regulated protein degradation in an equally important position. With the multitude of substrates targeted and processes involved, it is not surprising that aberrations in the pathway have been implicated in the pathogenesis of many diseases, among them certain malignancies, neurodegeneration, and disorders of the immune and inflammatory system. As a result, the system has become a platform for drug targeting, and mechanism-based drugs are currently developed, one of them is already on the market.

\section{The Lysosome and Intracellular Protein Degradation}

In the mid-1950s, Christian de Duve discovered the lysosome (see, e.g., de Duve et al., ${ }^{8}$ and Gianetto and de Duve ${ }^{9}$ and
Figure 1). The lysosome was first recognized biochemically in rat liver as a vacuolar structure that contains various hydrolytic enzymes, which function optimally at an acidic $\mathrm{pH}$. It is surrounded by a membrane that endows the contained enzymes latency that is required to protect the cellular contents from their action (see below). The definition of the lysosome has been broadened over the years. This is because it has been recognized that the digestive process is dynamic and involves numerous stages of lysosomal maturation together with the digestion of both exogenous proteins (which are targeted to the lysosome through receptormediated endocytosis and pinocytosis) and exogenous particles (which are targeted via phagocytosis; the two processes are known as heterophagy), as well as digestion of endogenous proteins and cellular organelles (which are targeted by micro- and macroautophagy; see Figure 2). The lysosomal/vacuolar system as we currently recognize is a discontinuous and heterogeneous digestive system that also includes structures that are devoid of hydrolases - for example, early endosomes which contain endocytosed receptor-ligand complexes and pinocytosed/phagocytosed extracellular contents. On the other extreme, it includes the residual bodies - the end products of the completed digestive processes of heterophagy and autophagy. In between these extremes one can observe primary/nascent lysosomes that have not yet been engaged yet in any proteolytic process; early autophagic vacuoles that might contain intracellular organelles; intermediate/late endosomes and phagocytic vacuoles (heterophagic vacuoles) that contain extracellular

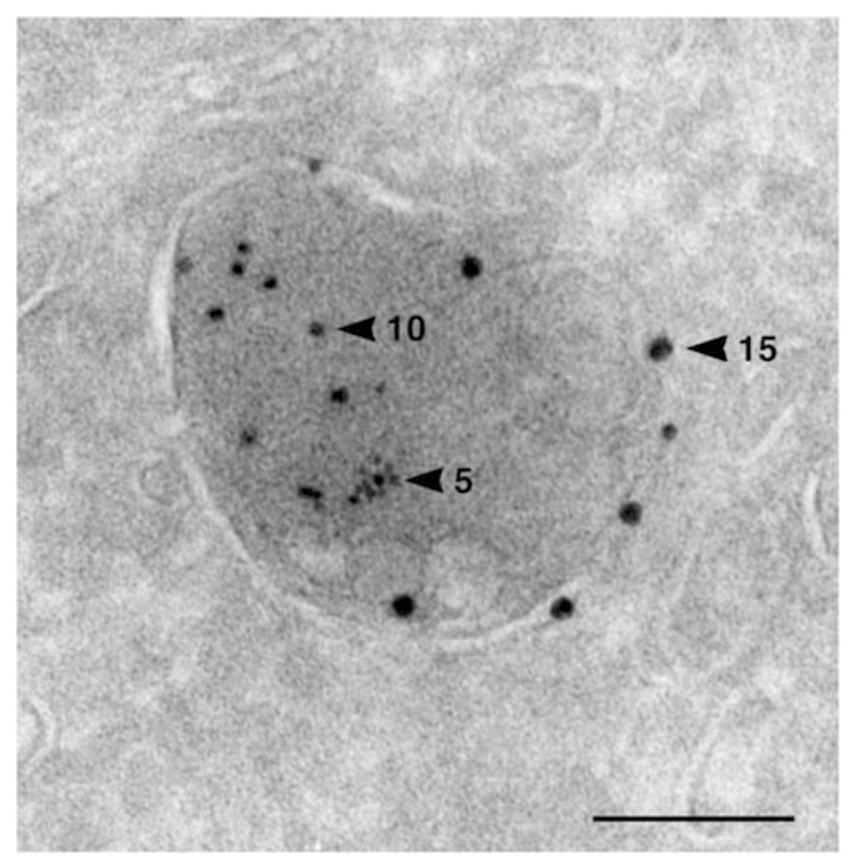

Figure 1 The lysosome: ultrathin cryosection of a rat PC12 cell that had been loaded for $1 \mathrm{~h}$ with bovine serum albumin (BSA)-gold ( $5 \mathrm{~nm}$ particles) and immunolabelled for the lysosomal enzyme cathepsin B (10-nm particles) and the lysosomal membrane protein LAMP1 (15 nm particles). Lysosomes are recognized also by their typical dense content and multiple internal membranes. Bar, $100 \mathrm{~nm}$. Courtesy of Viola Oorschot and Judith Klumperman, Department of Cell Biology, University Medical Centre Utrecht, The Netherlands 


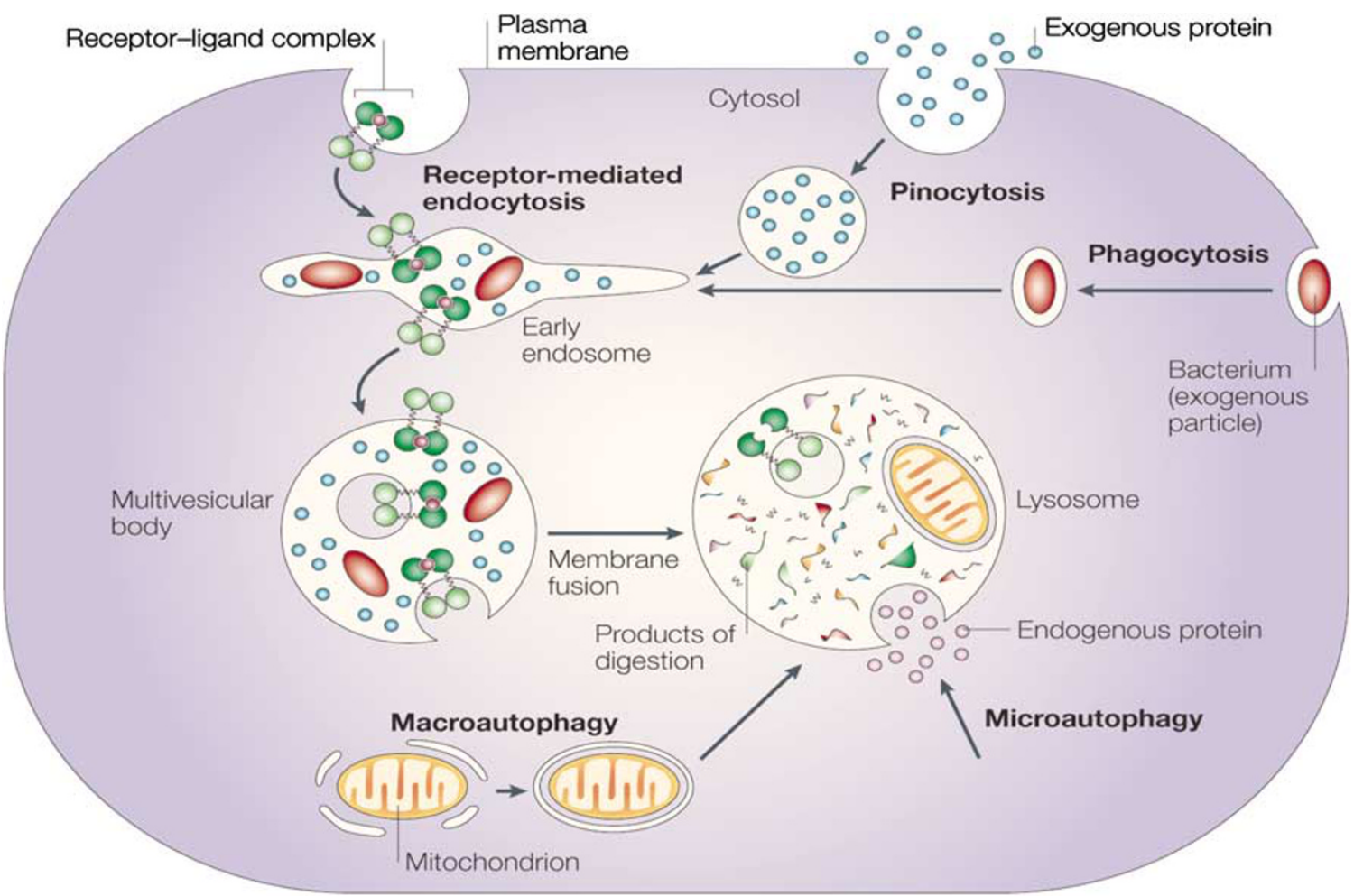

Figure 2 The four digestive processes mediated by the lysosome: (i) specific receptor-mediated endocytosis, (ii) pinocytosis (nonspecific engulfment of cytosolic droplets containing extracellular fluid), (iii) phagocytosis (of extracellular particles), and (iv) autophagy (micro- and macro-; of intracellular proteins and organelles) (with permission from Nature Publishing Group, copyright MacMillan Magazines Ltd. Published originally in Ciechanover ${ }^{83}$ )

contents/particles; and multivesicular bodies (MVBs), which are the transition vacuoles between endosomes/phagocytic vacuoles and the digestive lysosomes.

The discovery of the lysosome along with independent experiments that were carried out at the same time and that have further strengthened the notion that cellular proteins are indeed in a constant state of synthesis and degradation (see, e.g., Simpson ${ }^{10}$ ), led scientists to feel, for the first time, that they have at hand an organelle that can potentially mediate degradation of intracellular proteins. The fact that the proteases were separated from their substrates by a membrane provided an explanation for controlled degradation, and the only problem left to be explained was how the substrates are translocated into the lysosomal lumen, exposed to the activity of the lysosomal proteases and degraded. An important discovery in this respect was the unravelling of the basic mechanism of action of the lysosome - autophagy (reviewed in Mortimore and Poso ${ }^{11}$ ). Under basal metabolic conditions, portions of the cytoplasm, which contain the entire cohort of cellular proteins, are segregated within a membrane-bound compartment, and are then fused to a primary nascent lysosome and their contents digested. This process was denoted microautophagy. Under more extreme conditions, for example starvation, mitochondria, endoplasmic reticulum membranes, glycogen bodies and other cytoplasmic entities can also be engulfed by a process called macroautophagy (see, e.g., Ashford and Porter ${ }^{12}$; the different modes of action of the lysosome in digesting extra- and intracellular proteins are shown in Figure 2).
However, over a period of more than two decades, between the mid-1950s and the late 1970s, it has become gradually more and more difficult to explain several aspects of intracellular protein degradation based on the known mechanisms of lysosomal activity: accumulating lines of independent experimental evidence indicated that the degradation of at least certain classes of cellular proteins must be nonlysosomal. Yet, in the absence of any 'alternative', researchers came up with different explanations, some more substantiated and others less, to defend the 'lysosomal' hypothesis.

First was the gradual discovery, coming from different laboratories, that different proteins vary in their stability and their half-life times can span three orders of magnitude, from a few minutes to many days. Thus, the $t_{1 / 2}$ of ornitihine decarboxylase (ODC) is $\sim 10 \mathrm{~min}$, while that of glucose-6phosphate dehydrogenase (G6PD) is $15 \mathrm{~h}$ (for review articles, see, e.g., Schimke and Doyle, ${ }^{13}$ and Goldberg and St John ${ }^{14}$ ). Also, the rates of degradation of many proteins were shown to change with changing physiological conditions, such as availability of nutrients or hormones. It was conceptually difficult to reconcile the findings of distinct and changing halflives of different proteins with the mechanism of action of the lysosome, where the microautophagic vesicle contains the entire cohort of cellular (cytosolic) proteins that are therefore expected to degrade at the same rate. Similarly, changing pathophysiological conditions, such as starvation or resupplementation of nutrients, were expected to affect the stability of all cellular proteins to the same extent. Clearly, this was not the case. 
Another source of concern about the lysosome as the organelle in which intracellular proteins are degraded was the finding that specific and general inhibitors of lysosomal proteases have different effects on different populations of proteins, making it clear that distinct classes of proteins are targeted by different proteolytic machineries. Thus, the degradation of endocytosed/pinocytosed extracellular proteins was significantly inhibited, a partial effect was observed on the degradation of long-lived cellular proteins, and almost no effect was observed on the degradation of short-lived and abnormal/mutated proteins.

Finally, the thermodynamically paradoxical observation that the degradation of cellular proteins requires metabolic energy, and more importantly, the emerging evidence that the proteolytic machinery uses the energy directly, were in contrast with the known mode of action of lysosomal proteases that under the appropriate acidic conditions, and similar to all known proteases, degrade proteins in an exergonic manner.

The assumption that the degradation of intracellular proteins is mediated by the lysosome was nevertheless logical. Proteolysis results from direct interaction between the target substrates and proteases, and therefore it was clear that active proteases cannot be free in the cytosol, which would have resulted in destruction of the cell. Thus, it was recognized that any suggested proteolytic machinery that mediates degradation of intracellular proteins must also be equipped with a mechanism that separates - physically or virtually - the proteases and their substrates, and enables them to associate only when needed. The lysosomal membrane provided this fencing mechanism. Obviously, nobody could have predicted that a new mode of posttranslational modification - ubiquitination - could function as a proteolysis signal, and that untagged proteins will remain protected. Thus, while the structure of the lysosome could explain the separation necessary between the proteases and their substrates, and autophagy could explain the mechanism of entry of cytosolic proteins into the lysosomal lumen, major problems have remained unsolved. Important among them were: (i) the varying half-lives, (ii) the energy requirement, and (iii) the distinct response of different populations of proteins to lysosomal inhibitors. Thus, according to one model, it was proposed that different proteins have different sensitivities to lysosomal proteases, and their half-lives in vivo correlate with their sensitivity to the action of lysosomal proteases in vitro. ${ }^{15}$ To explain an extremely long half-life for a protein that is nevertheless sensitive to lysosomal proteases, or alterations in the stability of a single protein under various physiological states, it was suggested that although all cellular proteins are engulfed into the lysosome, only the short-lived proteins are degraded, whereas the long-lived proteins exit back into the cytosol: 'To account for differences in half-life among cell components or of a single component in various physiological states, it was necessary to include in the model the possibility of an exit of native components back to the extralysosomal compartment . ${ }^{16}$ According to a different model, selectivity is determined by the binding affinity of the different proteins for the lysosomal membrane, which controls their entry rates into the lysosome, and subsequently their degradation rates. ${ }^{17}$ For a selected group of proteins, such as the gluconeogenetic enzymes phosphoenol-pyruvate carboxykinase (PEPCK) and fructose-1,6-biphosphatase, it was suggested, though not firmly substantiated, that their degradation in the yeast vacuole is regulated by glucose via a mechanism called 'catabolite inactivation' that possibly involves their phosphorylation. However this regulated mechanism for vacuolar degradation is limited only to a small and specific group of proteins (see, e.g., Müller et al. ${ }^{18}$; reviewed in Holzer $^{19}$ ). More recent studies have shown that at least for stress-induced macroautophagy, a general sequence of amino acids, KFFERQ, directs, via binding to a specific 'receptor' and along with cytosolic and lysosomal chaperones, the regulated entry of many cytosolic proteins into the lysosomal lumen. While further corroboration of this hypothesis is still required, it explains the mass entry of a large population of proteins that contain a homologous sequence, but not the targeting for degradation of a specific protein under defined conditions (reviewed in Majeski and Dice, ${ }^{20}$ and Cuervo and Dice ${ }^{21}$ ). The energy requirement for protein degradation was described as indirect, and necessary, for example, for protein transport across the lysosomal membrane ${ }^{22}$ and/or for the activity of the $\mathrm{H}^{+}$pump and the maintenance of the low acidic intralysosomal $\mathrm{pH}$ that is necessary for optimal activity of the proteases. ${ }^{23}$ We now know that both mechanisms require energy. In the absence of any alternative, and with lysosomal degradation as the most logical explanation for targeting all known classes of proteins at the time, Christian de Duve summarized his view on the subject in a review article published in the mid-1960s, saying: 'Just as extracellular digestion is successfully carried out by the concerted action of enzymes with limited individual capacities, so, we believe, is intracellular digestion'. ${ }^{24}$ The problem of different sensitivities of distinct protein groups to lysosomal inhibitors has remained unsolved, and may have served as an important trigger in future quest for a nonlysosomal proteolytic system.

Progress in identifying the elusive, nonlysosomal proteolytic system(s) was hampered by the lack of a cell-free preparation that could faithfully replicate the cellular proteolytic events - degrading proteins in a specific and energyrequiring mode. An important breakthrough was made by Rabinovitz and Fisher, who found that rabbit reticulocytes degrade abnormal, amino-acid analogue-containing hemoglobin. ${ }^{25}$ Their experiments modelled known disease states, the hemoglobinopathies. In these diseases, abnormal mutated hemoglobin chains (such as sickle cell hemoglobin) or excess of unassembled normal hemoglobin chains (which are synthesized normally, but also excessively in thalassemias, diseases in which the pairing chain is not synthesized at all or is mutated and rapidly degraded, and consequently the bi-heterodimeric hemoglobin complex is not assembled) are rapidly degraded in the reticulocyte. ${ }^{26,27}$ Reticulocytes are terminally differentiating red blood cells that do not contain lysosomes. Therefore, it was postulated that the degradation of hemoglobin in these cells is mediated by a nonlysosomal machinery. Etlinger and Goldberg ${ }^{28}$ were the first to isolate and characterize a cell-free proteolytic preparation from reticulocytes. The crude extract selectively degraded abnormal hemoglobin, required ATP hydrolysis, and acted optimally at a neutral $\mathrm{pH}$, which further corroborated the assumption that the proteolytic activity was of a nonlysosomal origin. 
A similar system was isolated and characterized later by Hershko, Ciechanover, and their co-workers. ${ }^{29}$ Additional studies by this group led subsequently to resolution, characterization and purification of the major enzymatic components from this extracts and to the discovery of the ubiquitin signalling system (see below).

\section{The Lysosome Hypothesis is Challenged}

As mentioned above, the unravelled mechanism(s) of action of the lysosome could explain only partially, and at times not satisfactorily, several key emerging characteristics of intracellular protein degradation. Among them were the heterogeneous stability of individual proteins, the effect of nutrients and hormones on their degradation, and the dependence of intracellular proteolysis on metabolic energy. The differential effect of selective inhibitors on the degradation of different classes of cellular proteins (see above but mostly below) could not be explained at all.

The evolution of methods to monitor protein kinetics in cells together with the development of specific and general lysosomal inhibitors has resulted in the identification of different classes of cellular proteins, long- and short-lived, and the discovery of the differential effects of the inhibitors on these groups (see, e.g., Knowles and Ballard, ${ }^{30}$ and Neff et al. $\left.{ }^{31}\right)$. An elegant experiment in this respect was carried out by Brian Poole and his co-workers in the Rockefeller University. Poole was studying the effect of lysosomotropic agents, weak bases such as ammonium chloride and chloroquine, that accumulate in the lysosome and dissipate its low acidic $\mathrm{pH}$. It was assumed that this mechanism underlies also the antimalarial activity of chloroquine and similar drugs where they inhibit the activity of parasite's lysosome, 'paralyzing' its ability to digest the host's hemoglobin during the intraerythrocytic stage of its life cycle. Poole and his co-workers metabolically labelled endogenous proteins in living macrophages with ${ }^{3} \mathrm{H}$-labelled leucine and 'fed' them with dead macrophages that had been previously labelled with ${ }^{14} \mathrm{C}$-leucine. They assumed, apparently correctly, that the dead macrophages debris and proteins will be phagocytosed by live macrophages and targeted to the lysosome for degradation. They monitored the effect of lysosomotropic agents on the degradation of these two protein populations. In particular, they studied the effect of the weak bases chloroquine and ammonium chloride (which enter the lysosome and neutralize the $\mathrm{H}^{+}$ions), and the acid ionophore $\mathrm{X} 537 \mathrm{~A}$, which dissipates the $\mathrm{H}^{+}$gradient across the lysosomal membrane. They found that these drugs specifically inhibited the degradation of extracellular proteins, but not that of intracellular proteins. ${ }^{32}$ Poole summarized these experiments and explicitly predicted the existence of a nonlysosomal proteolytic system that degrades intracellular proteins: 'Some of the macrophages labelled with tritium were permitted to endocytise the dead macrophages labelled with 14C. The cells were then washed and replaced in fresh medium. In this way, we were able to measure in the same cells the digestion of macrophage proteins from two sources. The exogenous proteins will be broken down in the lysosomes, while the endogenous proteins will be broken down wherever it is that endogenous proteins are broken down during protein turnover. ${ }^{33}$

The requirement for metabolic energy for the degradation of both prokaryotic ${ }^{34}$ and eukaryotic ${ }^{10,35}$ proteins was difficult to understand. Proteolysis is an exergonic process and the thermodynamically paradoxical energy requirement for intracellular proteolysis made researchers believe that energy cannot be consumed directly by proteases or the proteolytic process per se, and is used indirectly. As Simpson summarized his findings: ${ }^{10}$ "The data can also be interpreted by postulating that the release of amino acids from protein is itself directly dependent on energy supply. A somewhat similar hypothesis, based on studies on autolysis in tissue minces, has recently been advanced, but the supporting data are very difficult to interpret. However, the fact that protein hydrolysis as catalyzed by the familiar proteases and peptidases occurs exergonically, together with the consideration that autolysis in excised organs or tissue minces continues for weeks, long after phosphorylation or oxidation ceased, renders improbable the hypothesis of the direct energy dependence of the reactions leading to protein breakdown'. Being cautious, however, and probably unsure about this unequivocal conclusion, Simpson still left a narrow orifice opened for a proteolytic process that requires energy in a direct manner: 'However, the results do not exclude the existence of two (or more) mechanisms of protein breakdown, one hydrolytic, the other energy-requiring'. Since any proteolytic process must be at one point or another hydrolytic, the statement that makes a distinction between a hydrolytic process and an energy-requiring, yet nonhydrolytic one, is not clear. Judging the statement from a historical point of view and knowing the mechanism of action of the ubiquitin system, where energy is required also in the prehydrolytic step (ubiquitin conjugation), Simpson may have thought of a two-step mechanism, but did not give it a clear description. At the end of this clearly understandable and apparently difficult deliberation, he left us with a vague explanation linking protein degradation to protein synthesis, a process that was known to require metabolic energy: 'The fact that a supply of energy seems to be necessary for both the incorporation and the release of amino acids from protein might well mean that the two processes are interrelated. Additional data suggestive of such a view are available from other types of experiments. Early investigations on nitrogen balance by Benedict, Folin, Gamble, Smith, and others point to the fact that the rate of protein catabolism varies with the dietary protein level. Since the protein level of the diet would be expected to exert a direct influence on synthesis rather than breakdown, the altered catabolic rate could well be caused by a change in the rate of synthesis'. ${ }^{10}$ With the discovery of lysosomes in eukaryotic cells it could be argued that energy is required for the transport of substrates into the lysosome or for maintenance of the low intralysosomal $\mathrm{pH}$ (see above), for example. The observation by Hershko and Tomkins that the activity of tyrosine aminotransferase (TAT) was stabilized following depletion of ATP $^{35,36}$ indicated that energy may be required at an early stage of the proteolytic process, most probably before proteolysis occurs. Yet, it did not provide a clue as for the mechanism involved: energy could be used, for example, for specific modification of TAT, for example phosphorylation, 
that would sensitize it to degradation by the lysosome or by a yet unknown proteolytic mechanism, or for a modification that activates its putative protease. It could also be used for a more general lysosomal mechanism, one that involves transport of TAT into the lysosome, for example. The energy inhibitors inhibited almost completely degradation of the entire population of cell proteins, confirming previous studies (e.g. Simpson ${ }^{10}$ ) and suggesting a general role for energy in protein catabolism. Yet, an interesting finding was that energy inhibitors had an effect that was distinct form that of protein synthesis inhibitors which affected only enhanced degradation (induced by steroid hormone depletion), but not basal degradation. This finding ruled out, at least partially, a tight linkage between protein synthesis and degradation. In bacteria, which lack lysosomes, an argument involving energy requirement for lysosomal degradation could not have been proposed, but other indirect effects of ATP hydrolysis could have affected proteolysis in E. coli, such as phosphorylation of substrates and/or proteolytic enzymes, or maintenance of the 'energized membrane state'. According to this model, proteins could become susceptible to proteolysis by changing their conformation, for example, following association with the cell membrane that maintains a local, energy-dependent gradient of a certain ion. While such an effect was ruled out, ${ }^{37}$ and since there was no evidence for a phosphorylation mechanism (although the proteolytic machinery in prokaryotes had not been identified at that time), it seemed that at least in bacteria, energy is required directly for the proteolytic process. In any event, the requirement for metabolic energy for protein degradation in both prokaryotes and eukaryotes, a process that is exergonic thermodynamically, strongly indicated that in cells proteolysis is highly regulated, and that a similar principle/mechanism has been preserved along evolution of the two kingdoms. Implying from the possible direct requirement for ATP in degradation of proteins in bacteria, it was not too unlikely to assume a similar direct mechanism in the degradation of cellular proteins in eukaryotes. Supporting this notion was the description of the cellfree proteolytic system in reticulocytes, ${ }^{28,29}$ a cell that lacks lysosomes, which indicated that energy is probably required directly for the proteolytic process, although here too, the underlying mechanisms had remained enigmatic at the time. Yet, the description of the cell-free system paved the road for detailed dissection of the underlying mechanisms involved.

\section{The Ubiquitin-Proteasome System}

The cell-free proteolytic system from reticulocytes ${ }^{28,29}$ turned out to be an important and rich source for the purification and characterization of the enzymes that are involved in the ubiquitin-proteasome system. Initial fractionation of the crude reticulocyte cell extract on the anion-exchange resin diethylaminoethyl cellulose yielded two fractions, which were both required to reconstitute the energy-dependent proteolytic activity that is found in the crude extract: The unadsorbed, flow through material was denoted fraction I, and the high salt eluate of the adsorbed proteins which was denoted fraction II (Table 1). ${ }^{38}$ This was an important observation and a lesson for the future dissection of the system. For one it suggested
Table 1 Resolution of the ATP-dependent proteolytic activity from crude reticulocyte extract into two essentially required complementing activities (adapted from Ciechanover et al.; ${ }^{38}$ with permission from Elsevier/Biochem. Biophys. Res. Commun.)

\begin{tabular}{lcc}
\hline Fraction & \multicolumn{2}{c}{ Degradation of $\left[{ }^{3} \mathrm{H}\right]$ globin (\%) } \\
\cline { 2 - 3 } & - ATP & +ATP \\
\hline Lysate & 1.5 & 10 \\
Fraction I & 0.0 & 0.0 \\
Fraction II & 1.5 & 2.7 \\
Fraction I and Fraction II & 1.6 & 10.6 \\
\hline
\end{tabular}

that the system is not composed of a single 'classical' protease that has evolved evolutionarily to acquire energy dependence (although such energy-dependent proteases, the mammalian $26 \mathrm{~S}$ proteasome (see below) and the prokaryotic Lon gene product have been described later), but that it is made of at least two components. This finding of a two-component, energy-dependent protease, left the researchers with no paradigm to follow, and in attempts to explain the finding, they suggested, for example, that the two fractions could represent an inhibited protease and its activator. Second, learning from this reconstitution experiment and the essential dependence between the two active components, we continued to reconstitute activity from resolved fractions whenever we encountered a loss of activity along further purification steps. This biochemical 'complementation' approach resulted in the discovery of additional enzymes of the system, all required to be present in the reaction mixture in order to catalyze the multistep proteolysis of the target substrate. We chose first to purify the active component from fraction I. It was found to be a small, $\sim 8.5$ $\mathrm{kDa}$ heat stable protein that was designated ATP-dependent Proteolysis Factor 1, APF-1. APF-1 was later identified as ubiquitin (see below; I am using the term APF-1 to the point in which it was identified as ubiquitin and then change terminology accordingly). In retrospect, the decision to start the purification efforts with fraction I turned out to be important, as fraction I contained only one single protein APF-1 - that was necessary to stimulate proteolysis of the model substrate we used at the time, while fraction II turned out to contain many more. Later studies showed that fraction I contains other components necessary for the degradation of other substrates, but these were not necessary for the reconstitution of the system at that time. This enabled us not only to purify APF-1 but also to quickly decipher its mode of action. If we would have started our purification efforts with fraction II, we would have encountered a significantly bumpier road. A critically important finding that paved the way for future developments in the field was that multiple moieties of APF-1 are covalently conjugated to the target substrate when incubated in the presence of fraction II, and the modification requires ATP (Ciechanover et al. ${ }^{39}$ and Hershko et al. ${ }^{40}$; Figures 3 and 4). It was also found that the modification is reversible, and APF-1 can be removed from the substrate or its degradation products. ${ }^{40}$

The discovery that APF-1 is covalently conjugated to protein substrates and stimulates their proteolysis in the presence of ATP and crude fraction II, led in 1980 to the 


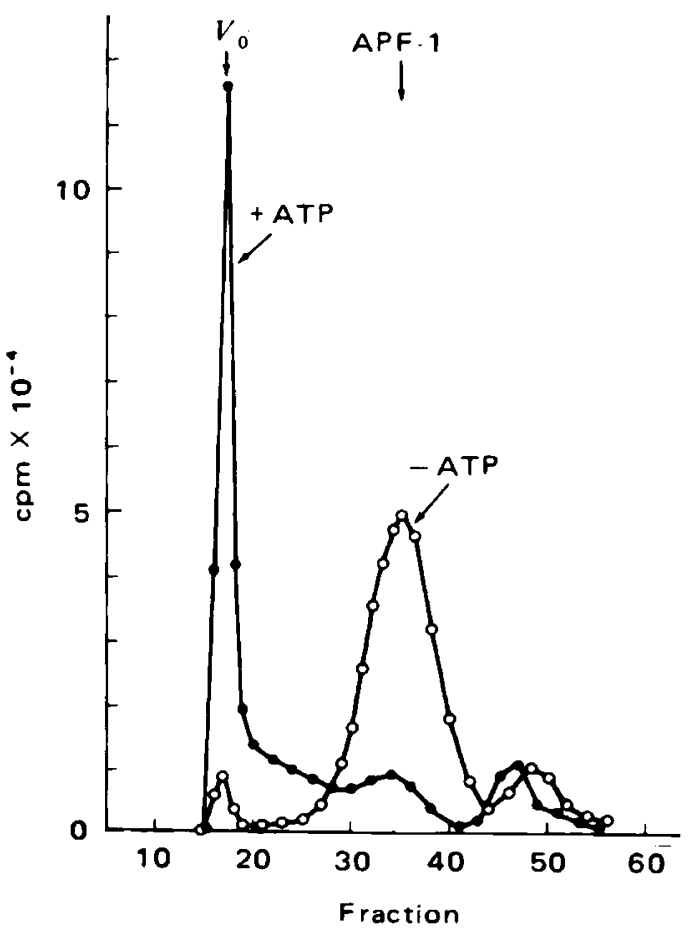

Figure 3 APF-1/ubiquitin is shifted to high molecular mass compound(s) following incubation in ATP-containing crude cell extract. ${ }^{125}$-labelled APF-1/ ubiquitin was incubated with reticulocyte crude Fraction II in the absence (open circles) or presence (closed circles) of ATP, and the reaction mixtures were resolved via gel filtration chromatography. The radioactivity measured in each fraction is shown. As can be seen, following addition of ATP, APF-1/ubiquitin becomes covalently attached to some component(s) in fraction II, which could be another enzyme of the system or its substrate(s) (with permission from Proceedings of the National Academy of the USA; published originally in Ciechanover et al. ${ }^{39}$ )

proposal of a model according to which protein substrate modification by multiple moieties of APF-1 targets it for degradation by a downstream, at that time unidentified, protease that cannot recognize the unmodified substrate; following degradation, reusable APF- 1 is released. ${ }^{40}$ Aminoacid analysis of APF-1, along with its known molecular mass and other general characteristics raised the suspicion that APF-1 is ubiquitin, ${ }^{41}$ a known protein of previously unknown function. Indeed, Wilkinson et al. ${ }^{42}$ confirmed unequivocally that APF-1 is indeed ubiquitin. Ubiquitin is a small, heat-stable and highly evolutionarily conserved protein of 76 residues. It was first purified during the isolation of thymopoietin ${ }^{43}$ and was subsequently found to be ubiquitously expressed in all kingdoms of living cells, including prokaryotes. ${ }^{44}$ Interestingly, it was initially found to have lymphocyte-differentiating properties, a characteristic that was attributed to the stimulation of adenylate cyclase. ${ }^{44,45}$ Accordingly, it was named UBIP for ubiquitous immunopoietic polypeptide. ${ }^{44}$ However, later studies showed that ubiquitin is not involved in the immune response, ${ }^{46}$ and that it was a contaminating endotoxin in the preparation that generated the adenylate cyclase and the T-cell differentiating activities. Furthermore, the sequence of several eubacteria and archaebacteria genomes as well as biochemical analyses in these organisms (unpublished) showed that ubiquitin is restricted only to

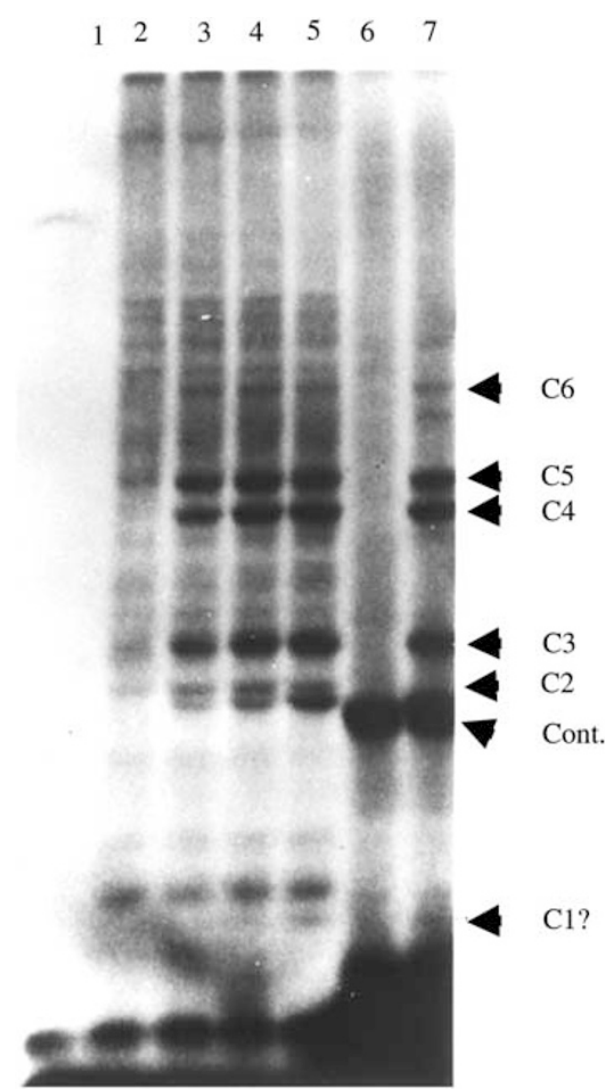

Figure 4 Multiple molecules of APF-1/ubiquitin are conjugated to the proteolytic substrate, probably signalling it for degradation. To interpret the data described in the experiment depicted in Figure 2 and to test the hypothesis that APF-1 is conjugated to the target proteolytic substrate, ${ }^{125}$ I-APF-1/ubiquitin was incubated along with crude Fraction II (Figure 3 and text) in the absence (lane 1) or presence (lanes 2-5) of ATP and in the absence (lanes 1,2) or presence (lanes $3-5)$ of increasing concentrations of unlabelled lysozyme. Reaction mixtures resolved in lanes 6 and 7 were incubated in the absence (lane 6) or presence (lane 7) of ATP, and included unlabelled APF-1/ubiquitin and ${ }^{125}$-labelled lysozyme. C1-C6 denote specific APF-1/ubiquitin-lysozyme adducts in which the number of APF-1/ubiquitin moieties bound to the lysozyme moiety of the adduct is increasing, probably from 1 to 6 . Reactions mixtures were resolved via sodium dodecyl sulfate-polyacrylamide gel electrophoresis (SDS-PAGE) and visualized following exposure to an X-ray film (autoradiography) (with permission from Proceedings of the National Academy of the USA; published originally in Hershko et al. ${ }^{40}$ )

eukaryotes. The finding of ubiquitin in bacteria ${ }^{44}$ was probably due to contamination of the bacterial extract with yeast ubiquitin derived from the yeast extract in which the bacteria were grown. While in retrospect the name ubiquitin is a misnomer, as it is restricted to eukaryotes and is not ubiquitous as was previously thought, from historical reasons it has still remained the name of the protein. Accordingly, and in order to avoid confusion, I suggest that the names of other novel enzymes and components of the ubiquitin system, but of other systems as well, should remain as were first coined by their discoverers.

An important development in the ubiquitin research field was the discovery that a single ubiquitin moiety can be covalently conjugated to histones, particularly to histones $\mathrm{H} 2 \mathrm{~A}$ and $\mathrm{H} 2 \mathrm{~B}$. While the function of these adducts has remained elusive until recently, their structure was unravelled in the 
mid-1970s. The structure of the ubiquitin conjugate of $\mathrm{H} 2 \mathrm{~A}$ (uH2A; was also designated protein A24) was deciphered by Goldknopf and Busch ${ }^{47,48}$ and by Hunt and Dayhoff, ${ }^{49}$ who found that the two proteins are linked through a fork-like, branched isopeptide bond between the carboxy-terminal glycine of ubiquitin (Gly ${ }^{76}$ ) and the $\varepsilon-\mathrm{NH}_{2}$ group of an internal lysine $\left(\right.$ Lys $\left.^{119}\right)$ of the histone molecule. The isopeptide bond found in the histone-ubiquitin adduct was suggested to be identical to the bond that was found between ubiquitin and the target proteolytic substrate ${ }^{50}$ and between the ubiquitin moieties in the polyubiquitin chain ${ }^{51,52}$ that is synthesized on the substrate and that functions as a proteolysis recognition signal for the downstream $26 \mathrm{~S}$ proteasome. In this particular polyubiquitin chain, the linkage is between $\mathrm{Gly}^{76}$ of one ubiquitin moiety and internal Lys ${ }^{48}$ of the previously conjugated moiety. Only Lys $^{48}$-based ubiquitin chains are recognized by the $26 \mathrm{~S}$ proteasome and serve as proteolytic signals. In recent years, it has been shown that the first ubiquitin moiety can also be attached in a linear mode to the $\mathrm{N}$-terminal residue of the proteolytic target substrate. ${ }^{53}$ However, the subsequent ubiquitin moieties are generating Lys $^{48}$-based polyubiquitin chain on the first linearly fused moiety. N-terminal ubiquitination is clearly required for targeting naturally occurring lysine-less proteins for degradation. Yet, several lysine-containing proteins have also been described that traverse this pathway, for example the musclespecific transcription factor MyoD. In these proteins the internal lysine residues are probably not accessible to the cognate ligases. Other types of polyubiquitin chains have also been described that are not involved in targeting the conjugated substrates for proteolysis. Thus, a Lys ${ }^{63}$-based polyubiquitin chain has been described that is probably necessary to activate transcription factors (reviewed recently in Muratani and Tansey ${ }^{54}$ ). Interestingly, the role of monoubiquitination of histones has also been identified recently and this modification is also involved in regulation of transcription, probably via modulation of the structure of the nucleosomes (for recent reviews, see, e.g., Zhang ${ }^{55}$ and Osley ${ }^{56}$ ).

The identification of APF-1 as ubiquitin, and the discovery that a high-energy isopeptide bond, similar to the one that links ubiquitin to histone $\mathrm{H} 2 \mathrm{~A}$, links it also to the target proteolytic substrate, resolved at that time the enigma of the energy requirement for intracellular proteolysis (see however below) and paved the road to the untangling of the complex mechanism of isopeptide bond formation. This process turned out to be similar to that of peptide bond formation that is catalyzed by tRNA synthetase following amino-acid activation during protein synthesis or during the nonribosomal synthesis of short peptides. ${ }^{57}$ Using the unravelled mechanism of ubiquitin activation and immobilized ubiquitin as a 'covalent' affinity bait, the three enzymes that are involved in the cascade reaction of ubiquitin conjugation were purified by Ciechanover, Hershko, and their co-workers. These enzymes are: (i) E1, the ubiquitin-activating enzyme; (ii) E2, the ubiquitin-carrier protein; and (iii) E3, the ubiquitin-protein ligase. ${ }^{58,59}$ The discovery of an E3, which is a specific substrate-binding component, indicated a possible solution to the problem of the varying stabilities of different proteins they might be specifically recognized and targeted by different ligases.
In a short period, the ubiquitin tagging hypothesis received substantial support. For example, Chin and co-workers injected into HeLa cells labelled ubiquitin and hemoglobin and denatured the injected hemoglobin by oxidizing it with phenylhydrazine. They found that ubiquitin conjugation to globin is markedly enhanced by denaturation of hemoglobin and the concentration of globin-ubiquitin conjugates was proportional to the rate of hemoglobin degradation. ${ }^{60}$ Hershko et $a l^{61}$ observed a similar correlation for abnormal, aminoacid analogue-containing short-lived proteins. A previously isolated cell cycle arrest mutant that loses the ubiquitinhistone $\mathrm{H} 2 \mathrm{~A}$ adduct at the permissive temperature ${ }^{62}$ was found by Finley, Ciechanover and Varshavsky to harbor a thermolabile E1. ${ }^{63}$ Following heat inactivation, the cells fail to degrade normal short-lived proteins. ${ }^{64}$ Although the cells did not provide direct evidence for substrate ubiquitination as a destruction signal, they still provided the strongest direct linkage between ubiquitin conjugation and degradation.

At this point, the only missing link was the identification of the downstream protease that would specifically recognize ubiquitinated substrates. Tanaka et al. ${ }^{65}$ identified a second ATP-requiring step in the reticulocyte proteolytic system, which occurred after ubiquitin conjugation, and Hershko et al. ${ }^{66}$ demonstrated that the energy is required for conjugate degradation. An important advance in the field was a discovery by Hough and co-workers, who partially purified and characterized a high-molecular mass alkaline protease that degraded ubiquitin adducts of lysozyme but not untagged lysozyme, in an ATP-dependent mode. ${ }^{67}$ This protease which was later called the $26 \mathrm{~S}$ proteasome (see below) provided all the necessary criteria for being the specific proteolytic arm of the ubiquitin system. This finding was confirmed, and the protease was further characterized by Waxman et al., ${ }^{68}$ who found that it is an unusually large, $\sim 1.5 \mathrm{MDa}$ enzyme, unlike any other known protease. A further advance in the field was the discovery ${ }^{69}$ that a smaller neutral multisubunit 205 protease complex that was discovered together with the larger 26S complex, is similar to a 'multicatalytic proteinase complex' (MCP) that was described earlier in bovine pituitary gland by Wilk and Orlowski. ${ }^{70}$ This $20 \mathrm{~S}$ protease is ATPindependent and has different catalytic activities, cleaving on the carboxy-terminal side of hydrophobic, basic and acidic residues. Hough et al. ${ }^{69}$ raised the possibility - although they did not show it experimentally - that this $20 \mathrm{~S}$ protease can be a part of the larger $26 \mathrm{~S}$ protease that degrades the ubiquitin adducts. Later studies showed that indeed, the $20 \mathrm{~S}$ complex is the core catalytic particle of the larger $26 \mathrm{~S}$ complex. ${ }^{71,72}$ However, a strong evidence that the active 'mushroom'shaped 26S protease is generated through the assembly of two distinct subcomplexes - the catalytic 20S cylinder-like MCP and an additional 19S ball-shaped subcomplex (that was predicted to have a regulatory role) - was provided only in the early 1990 s by Hoffman et al., ${ }^{73}$ who mixed the two purified particles and generated the active 265 enzyme.

The proteasome is a large, $26 \mathrm{~S}$, multicatalytic protease that degrades polyubiquitinated proteins to small peptides. It is composed of two subcomplexes: a $20 \mathrm{~S}$ core particle (CP) that carries the catalytic activity, and a regulatory $19 \mathrm{~S}$ regulatory particle (RP). The $20 \mathrm{~S} \mathrm{CP}$ is a barrel-shaped structure composed of four stacked rings, two identical outer $\alpha$ rings 
and two identical inner $\beta$ rings. The eukaryotic $\alpha$ and $\beta$ rings are composed each of seven distinct subunits, giving the $20 S$ complex the general structure of $\alpha_{1-7} \beta_{1-7} \beta_{1-7} \alpha_{1-7}$. The catalytic sites are localized to some of the $\beta$ subunits. Each extremity of the 20S barrel can be capped by a 19S RP each composed of 17 distinct subunits, nine in a 'base' subcomplex, and eight in a 'lid' subcomplex. One important function of the 19S RP is to recognize ubiquitinated proteins and other potential substrates of the proteasome. Several ubiquitinbinding subunits of the 19S RP have been identified, although their biological roles and mode of action have not been discerned. A second function of the 19S RP is to open an orifice in the $\alpha$ ring that will allow entry of the substrate into the proteolytic chamber. Also, since a folded protein would not be able to fit through the narrow proteasomal channel, it is assumed that the 19S particle unfolds substrates and inserts them into the 20S CP. Both the channel opening function and the unfolding of the substrate require metabolic energy, and indeed, the 19S RP 'base' contains six different ATPase subunits. Following degradation of the substrate, short peptides derived from the substrate are released, as well as reusable ubiquitin (for a scheme describing the ubiquitin system, see Figure 5; for the structure of the $26 \mathrm{~S}$ proteasome, see Figure 6).

\section{Concluding Remarks}

The evolution of proteolysis as a centrally important regulatory mechanism is a remarkable example for the evolution of a novel biological concept and the accompanying battles to

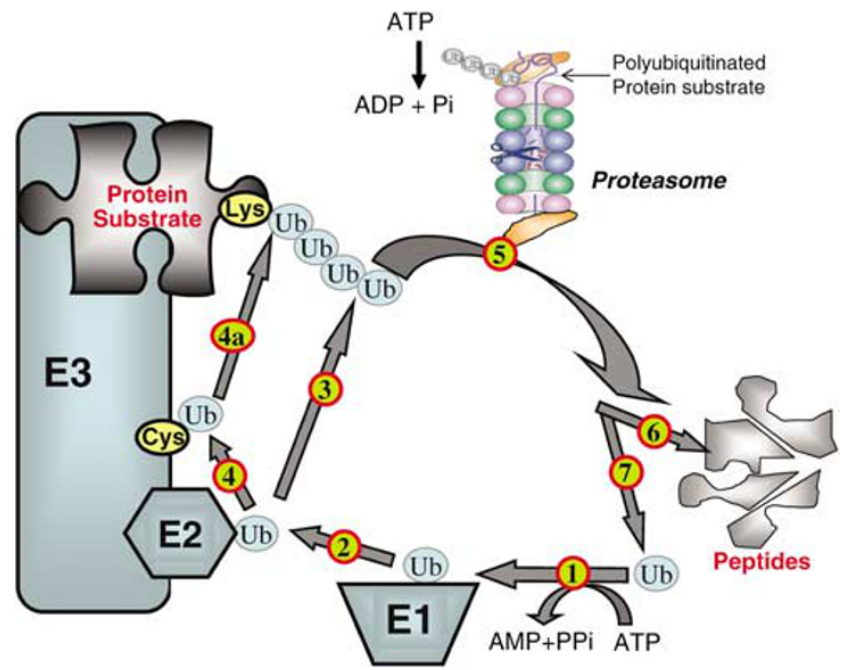

Figure 5 The ubiquitin-proteasome proteolytic system. Ubiquitin is activated by the ubiquitin-activating enzyme, E1 (1) followed by its transfer to a ubiquitincarrier protein (ubiquitin-conjugating enzyme, UBC), E2 (2). E2 transfers the activated ubiquitin moieties to the protein substrate that is bound specifically to a unique ubiquitin ligase E3. The transfer is either direct ((3) in the case of RING finger ligases) or via an additional thiol-ester intermediate on the ligase $((4,4 \mathrm{a})$ in case of HECT domain ligases). Successive conjugation of ubiquitin moieties to one another generates a polyubiquitin chain that serves as the binding (5) and degradation signal for the downstream $26 \mathrm{~S}$ proteasome. The substrate is degraded to short peptides (6), and free and reusable ubiquitin is released by de-ubiquitinating enzymes (DUBs) (7)
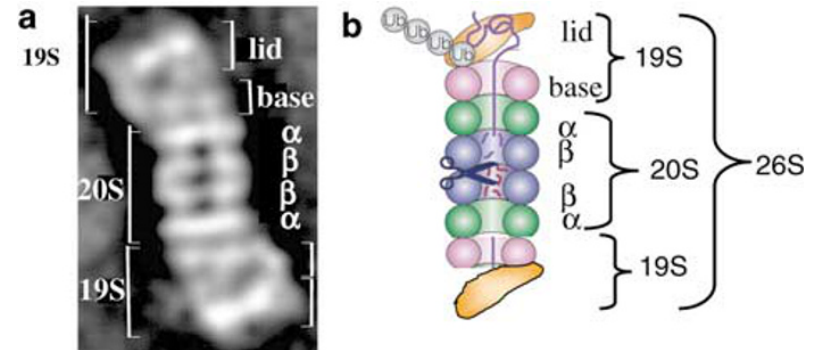

Figure 6 The Proteasome. The proteasome is a large, 26S, multicatalytic protease that degrades polyubiquitinated proteins to small peptides. It is composed of two subcomplexes: a $20 \mathrm{~S}$ core particle (CP) that carries the catalytic activity, and a regulatory $19 \mathrm{~S}$ regulatory particle (RP). The $20 \mathrm{~S} \mathrm{CP}$ is a barrel-shaped structure composed of four stacked rings, two identical outer $\alpha$ rings and two identical inner $\beta$ rings. The eukaryotic $\alpha$ and $\beta$ rings are composed each of seven distinct subunits, giving the 20S complex the general structure of $\alpha_{1-7} \beta_{1-7} \beta_{1-7} \alpha_{1-7}$. The catalytic sites are localized to some of the $\beta$ subunits. Each extremity of the 20S barrel can be capped by a 19S RP each composed of 17 distinct subunits, 9 in a 'base' subcomplex, and 8 in a 'lid' subcomplex. One important function of the 19S RP is to recognize ubiquitinated proteins and other potential substrates of the proteasome. Several ubiquitin-binding subunits of the 19S RP have been identified, however, their biological roles mode of action have not been discerned. A second function of the 19S RP is to open an orifice in the $\alpha$ ring that will allow entry of the substrate into the proteolytic chamber. Also, since a folded protein would not be able to fit through the narrow proteasomal channel, it is assumed that the 19S particle unfolds substrates and inserts them into the 20S CP. Both the channel opening function and the unfolding of the substrate require metabolic energy, and indeed, the 19S RP 'base' contains six different ATPase subunits. Following degradation of the substrate, short peptides derived from the substrate are released, as well as reusable ubiquitin (with permission from Nature Publishing Group copyright MacMillan Magazines Ltd. Published originally in Ciechanover ${ }^{83}$ ). (a) Electron microscopy image of the $26 \mathrm{~S}$ proteasome from the yeast $S$. cerevisiae. (b) Schematic representation of the structure and function of the 26SA proteasome

change paradigms. The five decade journey between the early 1940s and early 1990s began with fierce discussions on whether cellular proteins are static as has been thought for a long time, or are turning over. The discovery of the dynamic state of proteins was followed by the discovery of the lysosome, which was believed - between the mid-1950s and mid-1970s - to be the organelle within which intracellular proteins are destroyed. Independent lines of experimental evidence gradually eroded the lysosomal hypothesis and resulted in a new idea that the bulk of intracellular proteins are degraded - under basal metabolic conditions - via a nonlysosomal machinery. This resulted in the discovery of the ubiquitin system in the late 1970s and early 1980s.

With the identification of the reactions and enzymes that are involved in the ubiquitin-proteasome cascade, a new era in the protein degradation field began at the late 1980s and early 1990s. Studies that showed that the system is involved in targeting of key regulatory proteins - such as light-regulated proteins in plants, transcriptional factors, cell cycle regulators and tumor suppressors and promoters - started to emerge (see, e.g., Shanklin et al., ${ }^{74}$ Hochstrasser and Varshavsky, ${ }^{75}$ Scheffner et al., ${ }^{76}$ Glotzer et al., ${ }^{77}$ and Ciechanover et al. ${ }^{78}$ ). They were followed by numerous studies on the underlying mechanisms involved in the degradation of specific proteins, each with its own unique mode of recognition and regulation. The unravelling of the human genome revealed the existence of hundreds of distinct E3s, attesting to the complexity and the high specificity and selectivity of the system. Two important 
advances in the field were the discovery of the nonproteolytic functions of ubiquitin such as activation of transcription and routing of proteins to the vacuole, and the discovery of modification by ubiquitin-like proteins (UBLs), which are also involved in numerous nonproteolytic functions such as directing proteins to their subcellular destination, protecting proteins from ubiquitination, or controlling entire processes such as autophagy (see, e.g., Mizushima et al. ${ }^{79}$ ) (for the different roles of modifications by ubiquitin and UBLs, see Figure 7). All these studies have led to the emerging realization that this novel mode of covalent conjugation plays a key role in regulating a broad array of cellular process among them cell cycle and division, growth and differentiation, activation and silencing of transcription, apoptosis, the immune and inflammatory response, signal transduction, receptor mediated endocytosis, various metabolic pathways, and the cell quality control - through proteolytic and nonproteolytic mechanisms. The discovery that ubiquitin modification plays a role in routing proteins to the lysosome/ vacuole and that modification by specific and unique UBLs and modification system controls autophagy closed an exciting historical cycle, since it demonstrated that the two apparently distinct systems communicate with one another. With the many processes and substrates targeted by the ubiquitin pathway, it is not surprising to find that aberrations in the system underlie, directly or indirectly, the pathogenesis of many diseases. While inactivation of a major enzyme such as E1 is obviously lethal, mutations in enzymes or in recognition motifs in substrates that do not affect vital pathways or that affect the involved process only partially, may result in a broad array of phenotypes. Likewise, acquired changes in the activity of the system can also evolve into certain pathologies. The pathological states associated with the ubiquitin system can be classified into two groups: (a) those that result from loss of function - mutation in a ubiquitin system enzyme or in the recognition motif in the target substrate that results in stabilization of certain proteins; and (b) those that result from gain of function - abnormal or accelerated degradation of the protein target (for aberrations in the ubiquitin system that result in disease states, see Figure 8). Studies that employ targeted inactivation of genes coding for specific ubiquitin system enzymes and substrates in animals can provide a more systematic view into the broad spectrum of pathologies that may result from aberrations in ubiquitin-mediated a

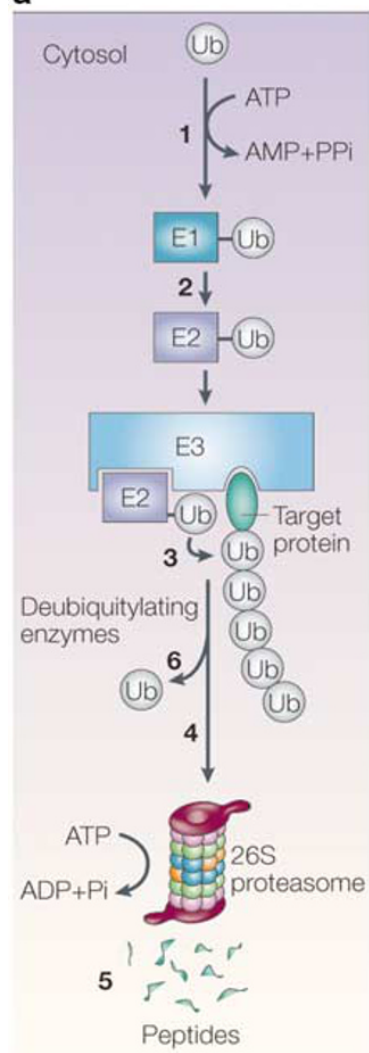

b

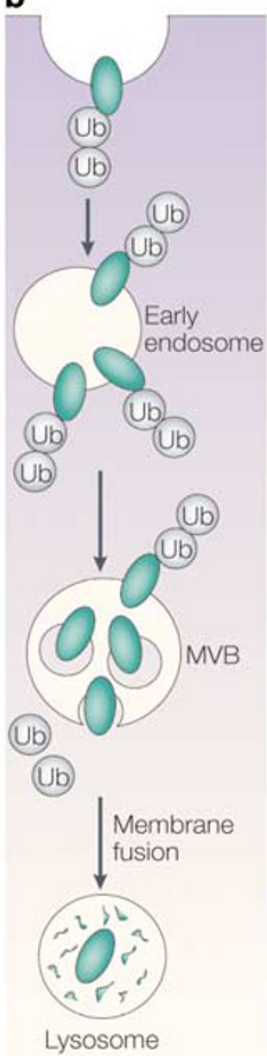

c

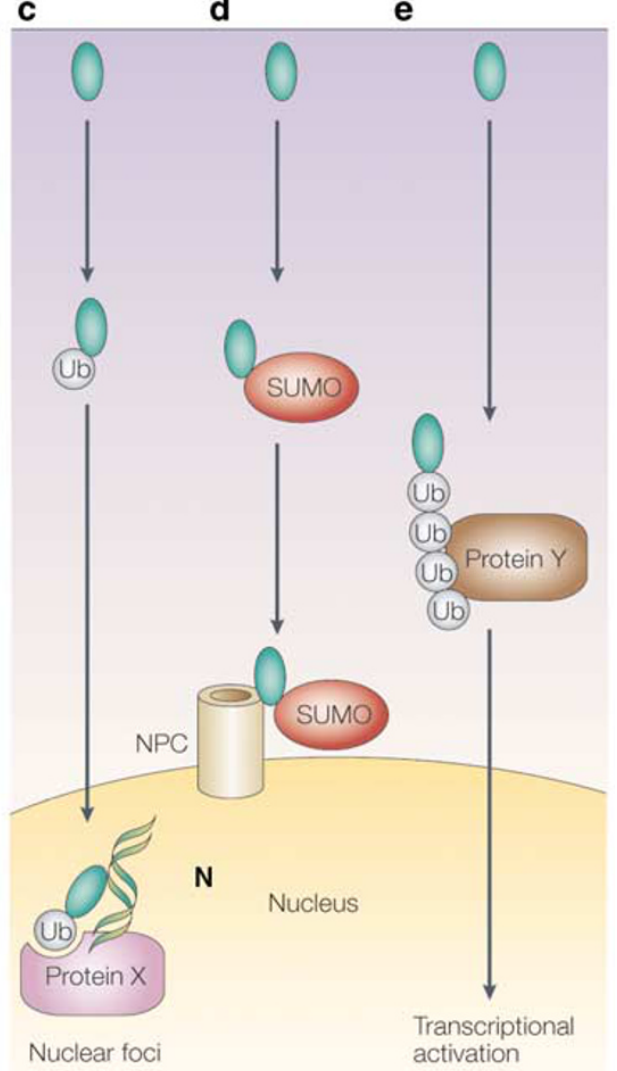

Figure 7 Some of the different functions of modification by ubiquitin and ubiquitin-like proteins. (a) Proteasomal-dependent degradation of cellular proteins (see Figure 4). (b) Mono or oligoubiquitination targets membrane proteins to degradation in the lysosome/vacuole. (c) Monoubiquitination, or (d) a single modification by a ubiquitin-like (UBL) protein, for example SUMO, can target proteins to different subcellular destinations such as nuclear foci or the nuclear pore complex (NPC). Modification by UBLs can serve other, nonproteolytic, functions, such as protecting proteins from ubiquitination or activation of E3 complexes. (e) Generation of a Lys ${ }^{63}$. based polyubiquitin chain can activate transcriptional regulators, directly or indirectly (via recruitment of other proteins (Protein Y; shown), or activation of upstream components such as kinases). Ub denotes ubiquitin, $\mathrm{K}$ denotes Lys, and S denotes Cys. (with permission from Nature Publishing Group, copyright MacMillan Magazines Ltd. Published originally in Ciechanover ${ }^{83}$ ) 


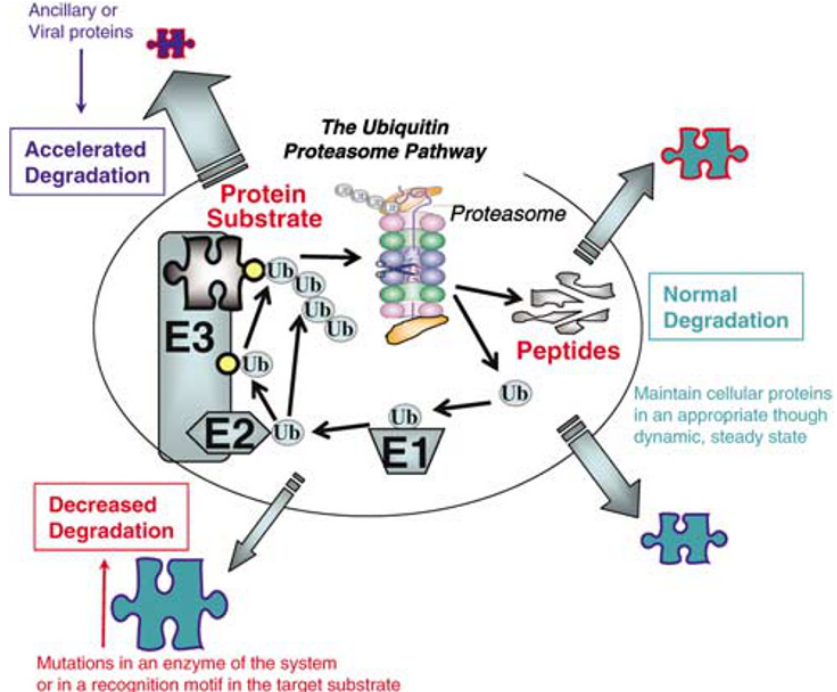

Figure 8 Aberrations in the ubiquitin-proteasome system and pathogenesis of human diseases. Normal degradation of cellular proteins maintains them in a steady-state level, though this level may change under various pathophysiological conditions (upper and lower right side). When degradation is accelerated due an increase in the level of an E3 (Skp2 in the case of p27, for example), or overexpression of an ancillary protein that generates a complex with the protein substrate and targets it for degradation (the Human Papillomavirus E6 oncoprotein that associates with p53 and targets it for degradation by the E6AP ligase, or the cytomegalovirus-encoded ER proteins US2 and US11 that target MHC class I molecules for ERAD), the steady-state level of the protein decreases (upper left side). A mutation in a ubiquitin ligase (such as occurs in Adenomatous Polyposis Coli - APC, or in E6-AP (Angelmans' Syndrome)) or in the substrate's recognition motif (such as occurs in $\beta$-catenin or in $\mathrm{ENaC}$ ) will result in decreased degradation and accumulation of the target substrate

proteolysis. Better understanding of the processes and identification of the components involved in the degradation of key regulatory proteins will lead to the development of mechanism-based drugs that will target specifically only the involved proteins. While the first drug, a specific proteasome inhibitor is already on the market, ${ }^{80}$ it appears that one important hallmark of the new era we are entering now will be the discovery of novel drugs based on targeting of specific processes such as inhibiting aberrant Mdm2- or E6-APmediated accelerated targeting of the tumor suppressor p53 which will lead to regain of its lost function.

Many reviews have been published on different aspects of the ubiquitin system. The purpose of this article was to bring to the reader several milestones along the historical pathway along which the ubiquitin system has been evolved. For additional reading on the ubiquitin system the reader is referred to the many reviews written on the system, among them for example are Glickman and Ciechanover ${ }^{81}$ Pickart and Cohen $^{82}$. Some parts of this review, including several figures, are based on another recently published review article $^{83}$.

\section{Acknowledgements}

Research in the laboratory of Aaron Ciechanover has been supported along the years by grants from the US-Israel Binational Science Foundation (BSF), the Israel Science Foundation (ISF) founded by the
Israeli National Academy of Humanities, Arts and Sciences, the GermanIsraeli Foundation (GIF) for Scientific Research and Development, the Israel Cancer Research Fund (ICRF) USA, the Deutsche-Israeli Cooperation Program (DIP), the European Union (EU), the Israel Cancer Society (ICS), the Prostate Cancer Foundation (PCF) - Israel, the Foundation for Promotion of Research in the Technion and various research grants administered by the Vice President of the Technion for Research. Infrastructural equipment for the laboratory of $A C$ and for the Cancer and Vascular Center has been purchased with the support of the Wolfson Charitable Fund - Center of Excellence for Studies on Turnover of Cellular Proteins and its Implications to Human Diseases. The review was obtained thanks to the kind help of the Nobel Foundation in Stockholm, http://nobelprize.org ( ${ }^{(}$The Nobel Foundation 2004).

\section{References}

1. Clarke HT (1958) Impressions of an organic chemist in biochemistry. Annu. Rev. Biochem. 27: 1-14

2. Kennedy EP (2001) Hitler's gift and the era of biosynthesis. J. Biol. Chem. 276: 42619-42631

3. Simoni RD, Hill RL and Vaughan M (2002) The use of isotope tracers to studyintermediary metabolism: Rudolf Schoenheimer. J. Biol. Chem. 277 e1e3 (available on-line at: http:/www.jbc.org )

4. Schoenheimer R, Ratner S and Rittenberg D (1939) Studies in protein metabolism: VII. The metabolism of tyrosine. J. Biol. Chem. 127: 333-344

5. Ratner S, Rittenberg D, Keston AS and Schoenheimer R (1940) Studies in protein metabolism: XIV. The chemical interaction of dietary Glycine and body proteins in rats. J. Biol. Chem. 134: 665-676

6. Schoenheimer R (1942) The Dynamic State of Body Constituents (Cambridge, MA, USA: Harvard University Press)

7. Hogness DS, Cohn M and Monod J (1955) Studies on the induced synthesis of $\beta$-galactosidase in Escherichia coli: The kinetics and mechanism of sulfur incorporation. Biochim. Biophys. Acta. 16: 99-116

8. de Duve C, Gianetto R, Appelmans F and Wattiaux R (1953) Enzymic content of the mitochondria fraction. Nature (London) 172: 1143-1144

9. Gianetto R and de Duve C (1955) Tissue fractionatin studies 4. Comparative study of the binding of acid phosphatase, $\beta$-glucoronidase and cathepsin by rat liver particles. Biochem. J. 59: 433-438

10. Simpson MV (1953) The release of labeled amino acids from proteins in liver slices. J. Biol. Chem. 201: 143-154

11. Mortimore GE and Poso AR (1987) Intracellular protein catabolism and its control during nutrient deprivation and supply. Annu. Rev. Nutr. 7: 539-564

12. Ashford TP and Porter KR (1962) Cytoplasmic components in hepatic cell lysosomes. J. Cell Biol. 12: 198-202

13. Schimke RT and Doyle D (1970) Control of enzyme levels in animal tissues. Annu. Rev. Biochem. 39: 929-976

14. Goldberg AL and St John AC (1976) Intracellular protein degradation in mammalian and bacterial cells: Part 2. Annu. Rev. Biochem. 45: 747-803

15. Segal HL, Winkler JR and Miyagi MP (1974) Relationship between degradation rates of proteins in vivo and their susceptibility to lysosomal proteases. J. Biol. Chem. 249: 6364-6365

16. Haider $M$ and Segal HL (1972) Some characteristics of the alanineaminotransferase and arginase-inactivating system of lysosomes. Arch. Biochem. Biophys. 148: 228-237

17. Dean RT (1977) Lysosomes, protein degradation. Acta Biol. Med. Ger. 36: 1815-1820

18. Müller M, Müller H and Holzer H (1981) Immunochemical studies on catabolite inactivation of phosphoenolpyruvate carboxykinase in Saccharomyces cerevisiae. J. Biol. Chem. 256: 723-727

19. Holzer H (1989) Proteolytic catabolite inactivation in Saccharomyces cerevisiae. Revis. Biol. Celular 21: 305-319

20. Majeski AE and Dice JF (2004) Mechanisms of chaperone-mediated autophagy. Intl. J. Biochem. Cell Biol. 36: 2435-2444

21. Cuervo AM and Dice JF (1998) Lysosomes, a meeting point of proteins, chaperones, and proteases. J. Mol. Med. 76: 6-12 
22. Hayashi M, Hiroi Y and Natori Y (1973) Effect of ATP on protein degradation in rat liver lysosomes. Nat. New Biol. 242: 163-166

23. Schneider DL (1981) ATP-dependent acidification of intact and disrupted lysosomes: evidence for an ATP-driven proton pump. J. Biol. Chem. 256 3858-3864

24. de Duve C and Wattiaux R (1966) Functions of lysosomes. Annu. Rev. Physiol. 28: 435-492

25. Rabinovitz M and Fisher JM (1964) Characteristics of the inhibition of hemoglobin synthesis in rabbit reticulocytes by threo- $\alpha$-amino- $\beta$-chlorobutyric acid. Biochim. Biophys. Acta 91: 313-322

26. Carrell RW and Lehmann H (1969) The unstable haemoglobin haemolytic anaemias. Semin. Hematol. 6: 116-132

27. Huehns ER and Bellingham AJ (1969) Diseases of function and stability of haemoglobin. Br. J. Haematol. 17: 1-10

28. Etlinger JD and Goldberg AL (1977) A soluble ATP-dependent proteolytic system responsible for the degradation of abnormal proteins in reticulocytes. Proc. Natl. Acad. Sci. USA 74: 54-58

29. Hershko A, Heller H, Ganoth D and Ciechanover A (1978) Mode of degradation of abnormal globin chains in rabbit reticulocytes In Protein Turnover and Lysosome Function Segal HL, Doyle DJ, eds (New York: Academic Press) pp. 149-169

30. Knowles SE and Ballard FJ (1976) Selective control of the degradation of normal and aberrant proteins in Reuber H35 hepatoma cells. Biochem. J. 156 609-617

31. Neff NT, DeMartino GN and Goldberg AL (1979) The effect of protease inhibitors and decreased temperature on the degradation of different classes of proteins in cultured hepatocytes. J. Cell Physiol. 101: 439-457

32. Poole B, Ohkuma S and Warburton MJ (1977) The accumulation of weakly basic substances in lysosomes and the inhibition of intracellular protein degradation. Acta Biol. Med. Germ. 36: 1777-1788

33. Poole B, Ohkuma S and Warburton MJ (1978) Some aspects of the intracellular breakdown of exogenous and endogenous proteins In Protein Turnover and Lysosome Function Segal HL, Doyle DJ, eds (New York: Academic Press) pp. 43-58

34. Mandelstam J (1958) Turnover of protein in growing and non-growing populations of Escherichia coli. Biochem. J. 69: 110-119

35. Steinberg D and Vaughan M (1956) Observations on intracellular protein catabolism studied in vitro. Arch. Biochem. Biophys. 65: 93-105

36. Hershko A and Tomkins GM (1971) Studies on the degradation of tyrosine aminotransferase in hepatoma cells in culture: influence of the composition of the medium and adenosine triphosphate dependence. J. Biol. Chem. 246: 710-714

37. Goldberg AL, Kowit JD and Etlinger JD (1976) Studies on the selectivity and mechanisms of intracellular protein degradation In Proteolysis and Physiological Regulation Ribbons DW, Brew K, eds (New York: Academic Press) pp. 313-337

38. Ciechanover A, Hod $Y$ and Hershko A (1978) A heat-stable polypeptide component of an ATP-dependent proteolytic system from reticulocytes. Biochem. Biophys. Res. Common. 81: 1100-1105

39. Ciechanover A, Heller H, Elias S, Haas AL and Hershko A (1980) ATPdependent conjugation of reticulocyte proteins with the polypeptide required for protein degradation. Proc. Natl. Acad. Sci. USA 77: 1365-1368

40. Hershko A, Ciechanover A, Heller H, Haas AL and Rose IA (1980) Proposed role of ATP in protein breakdown: conjugation of proteins with multiple chains of the polypeptide of ATP-dependent proteolysis. Proc. Natl. Acad. Sci. USA 77: 1783-1786

41. Ciechanover A, Elias S, Heller H, Ferber S and Hershko A (1980) Characterization of the heat-stable polypeptide of the ATP-dependent proteolytic system from reticulocytes. J. Biol. Chem. 255: 7525-7528

42. Wilkinson KD, Urban MK and Haas AL (1980) Ubiquitin is the ATP-dependent proteolysis factor I of rabbit reticulocytes. J. Biol. Chem. 255: 7529-7532

43. Goldstein $G$ (1974) Isolation of bovine thymin, a polypeptide hormone of the thymus. Nature (London) 247: 11-14

44. Goldstein G, Scheid M, Hammerling U, Schlesinger DH and Niall HD\& Boyse EA (1975) Isolation of a polypeptide that has lymphocyte-differentiating properties and is probably represented universally in living cells. Proc. Natl. Acad. Sci. USA 72: 11-15

45. Schlessinger DH, Goldstein G and Niall HD (1975) The complete amino acid sequence of ubiquitin, an adenylate cyclase stimulating polypeptide probably universal in living cells. Biochemistry 14: 2214-2218
46. Low TLK and Goldstein AL (1979) The chemistry and biology of thymosin: amino acid analysis of thymosin $\alpha 1$ and polypeptide $\beta 1$. J. Biol. Chem. 254: 987-995

47. Goldknopf IL and Busch H (1975) Remarkable similarities of peptide fingerprints of histone $2 \mathrm{~A}$ and non-histone chromosomal protein A24. Biochem. Biophys. Res. Commun. 65: 951-955

48. Goldknopf IL and Busch H (1977) Isopeptide linkage between non-histone and histone 2A polypeptides of chromosome conjugate-protein A24. Proc. Natl. Acad. Sci. USA 74: 864-868

49. Hunt LT and Dayhoff MO (1977) Amino-terminal sequence identity of ubiquitin and the non-histone component of nuclear protein A24. Biochim. Biophys. Res. Commun. 74: 650-655

50. Hershko A, Ciechanover A and Rose IA (1981) Identification of the active amino acid residue of the polypeptide of ATP-dependent protein breakdown. J. Biol. Chem. 256: 1525-1528

51. Hershko A and Heller $\mathrm{H}$ (1985) Occurrence of a polyubiquitin structure in ubiquitin-protein conjugates. Biochem. Biophys. Res. Common. 128: 1079-1086

52. Chau V, Tobias JW, Bachmair A, Mariott D, Ecker D, Gonda DK and Varshavsky A (1989) A multiubiquitin chain is confined to specific lysine in a targeted short-lived protein. Science 243: 1576-1583

53. Ciechanover A and Ben-Saadon R (2004) N-terminal ubiquitination: more protein substrates join in. Trends Cell Biol. 14: 103-106

54. Muratani M and Tansey WP (2003) How the ubiquitin-proteasome system controls transcription. Nat. Rev. Mol. Cell Biol. 4: 192-201

55. Zhang $Y$ (2003) Transcriptional regulation by histone ubiquitination and deubiquitination. Genes Dev. 17: 2733-2740

56. Osley MA (2004) H2B ubiquitylation: the end is in sight. Biochim. Biophys. Acta 1677: 74-78

57. Lipman $F$ (1971) Attempts to map a process evolution of peptide biosynthesis. Science 173: 875-884

58. Ciechanover A, Elias S, Heller H and Hershko A (1982) 'Covalent affinity' purification of ubiquitin-activating enzyme. J. Biol. Chem. 257: 2537-2542

59. Hershko A, Heller H, Elias S and Ciechanover A (1983) Components of ubiquitin-protein ligase system: resolution, affinity purification and role in protein breakdown. J. Biol. Chem. 258: 8206-8214

60. Chin DT, Kuehl L and Rechsteiner M (1982) Conjugation of ubiquitin to denatured hemoglobin is proportional to the rate of hemoglobin degradation in HeLa cells. Proc. Natl. Acad. Sci. USA 79: 5857-5861

61. Hershko A, Eytan E, Ciechanover A and Haas AL (1982) Immunochemical analysis of the turnover of ubiquitin-protein conjugates in intact cells: relationship to the breakdown of abnormal proteins. J. Biol. Chem. 257: 13964-13970

62. Matsumoto Y, Yasuda H, Marunouchi T and Yamada M (1983) Decrease in uH2A (protein A24) of a mouse temperature-sensitive mutant. FEBS Lett. 151: 139-142

63. Finley D, Ciechanover A and Varshavsky A (1984) Thermolability of ubiquitinactivating enzyme from the mammalian cell cycle mutant ts85. Cell 37: 43-55

64. Ciechanover A, Finley D and Varshavsky A (1984) Ubiquitin dependence of selective protein degradation demonstrated in the mammalian cell cycle mutant ts85. Cell 37: 57-66

65. Tanaka K, Waxman $L$ and Goldberg AL (1983) ATP serves two distinct roles in protein degradation in reticulocytes, one requiring and one independent of ATP. J. Cell Biol. 96: 1580-1585

66. Hershko A, Leshinsky E, Ganoth D and Heller H (1984) ATP-dependent degradation of ubiquitin-protein conjugates. Proc. Natl. Acad. Sci. USA 81: 1619-1623

67. Hough R, Pratt G and Rechsteiner M (1986) Ubiquitin-lysozyme conjugates. Identification and characterization of an ATP-dependent protease from rabbit reticulocyte lysates. J. Biol. Chem. 261: 2400-2408

68. Waxman L, Fagan J and Goldberg AL (1987) Demonstration of two distinct high molecular weight proteases in rabbit reticulocytes, one of which degrades ubiquitin conjugates. J. Biol. Chem. 262: 2451-2457

69. Hough R, Pratt G and Rechsteiner M (1987) Purification of two high molecular weight proteases from rabbit reticulocyte lysate. J. Biol. Chem. 262: 8303-8313

70. Wilk S and Orlowski M (1980) Cation-sensitive neutral endopeptidase: isolation and specificity of the bovine pituitary enzyme. J. Neurochem. 35: 1172-1182 
71. Eytan E, Ganoth D, Armon T and Hershko A (1989) ATP-dependent incorporation of $20 \mathrm{~S}$ protease into the $26 \mathrm{~S}$ complex that degrades proteins conjugated to ubiquitin. Proc. Natl. Acad. Sci. USA 86: 7751-7755

72. Driscoll J and Goldberg AL (1990) The proteasome (multicatalytic protease) is a component of the $1500-\mathrm{kDa}$ proteolytic complex which degrades ubiquitinconjugated proteins. J. Biol. Chem. 265: 4789-4792

73. Hoffman L, Pratt $G$ and Rechsteiner M (1992) Multiple forms of the $20 \mathrm{~S}$ multicatalytic and the $26 \mathrm{~S}$ ubiquitin/ATP-dependent proteases from rabbit reticulocyte lysate. J. Biol. Chem. 267: 22362-22368

74. Shanklin J, Jaben M and Vierstra RD (1987) Red light-induced formation of ubiquitin-phytochrome conjugates: identification of possible intermediates of phytochrome degradation. Proc. Natl. Acad. Sci. USA 84: 359-363

75. Hochstrasser M and Varshavsky A (1990) In vivo degradation of a transcriptional regulator: the yeast $\alpha 2$ repressor. Cell 61: 697-708

76. Scheffner M, Werness BA, Huibregtse JM, Levine AJ and Howley PM (1990) The E6 oncoprotein encoded by human papillomavirus types 16 and 18 promotes the degradation of p53. Cell 63: 1129-1136
77. Glotzer M, Murray AW and Kirschner MW (1991) Cyclin is degraded by the ubiquitin pathway. Nature 349: 132-138

78. Ciechanover A, DiGiuseppe JA, Bercovich B, Orian A, Richter JD, Schwartz AL and Brodeur GM (1991) Degradation of nuclear oncoproteins by the ubiquitin system in vitro. Proc. Natl. Acad. Sci. USA 88: 139-143

79. Mizushima N, Noda T, Yoshimori T, Tanaka Y, Ishii T, George MD, Klionsky DJ, Ohsumi M and Ohsumi Y (1998) A protein conjugation system essential for autophagy. Nature 395: 395-398

80. Adams J (2003) Potential for proteasome inhibition in the treatment of cancer. Drug Discov. Today 8: 307-315

81. Glickman $\mathrm{MH}$ and Ciechanover A (2002) The ubiquitin-proteasome pathway: destruction for the sake of construction. Physiol Rev 82: 373428

82. Pickart CM and Cohen RE (2004) Proteasomes and their kin: proteases in the machine age. Nat. Rev. Mol. Cell Biol. 5: 177-187

83. Ciechanover A (2005) From the lysosome to ubiquitin and the proteasome. Nat. Rev. Mol. Cell Biol. 6: 79-86 